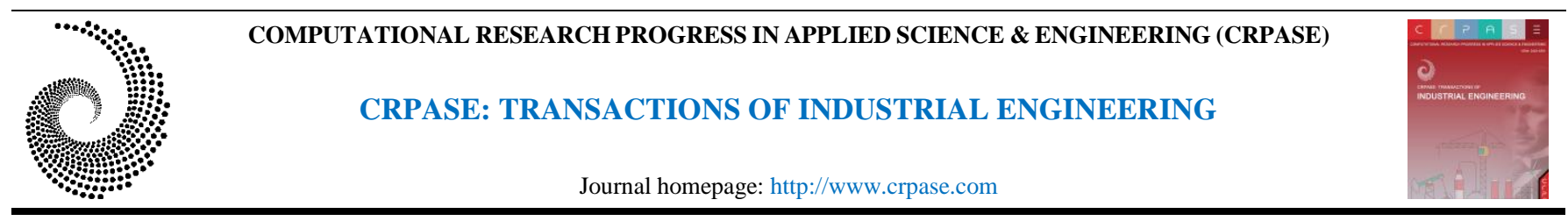

\title{
Mathematical Modeling in Disaster Logistics: Multi-Depot Vehicle Routing Problem
}

\author{
Zeliha Mahmat ${ }^{1 *}$, Lutfu S. Sua ${ }^{2}$, Figen Balo ${ }^{3}$ \\ ${ }^{1}$ Department of Industrial Engineering, Firat University \\ ${ }^{2}$ School of Entrepreneurship and Business Administration, American University of Central Asia \\ ${ }^{3}$ Department of Industrial Engineering, Firat University
}

\begin{tabular}{ll}
\hline Keywords & Abstract \\
\cline { 2 - 3 } $\begin{array}{l}\text { Disaster Logistics, } \\
\text { Cluster Coverage, } \\
\text { MDVRP, }\end{array}$ & $\begin{array}{l}\text { Disasters are unforeseen situations that cause serious material losses and damages in } \\
\text { addition to the dead and injured when they occur. Since disasters cannot be predicted in } \\
\text { ambulance Routing, } \\
\text { Mathematical Modeling. }\end{array}$ \\
$\begin{array}{l}\text { most important aspect of such studies is the development and examination of post-disaster } \\
\text { search and rescue activities and treatment facilities. One of the most important issues to be } \\
\text { considered while performing these operations is to reach the disaster victims in minimum } \\
\text { time and to plan disaster logistics in the most efficient manner possible. In this study, the } \\
\text { problem of planning debris scanning activities with Unmanned Aerial Vehicles after an } \\
\text { earthquake and transporting the injured people to the hospitals by ambulances in minimum } \\
\text { time was discussed and mathematical models were developed to solve the problem. The } \\
\text { ambulance routing problem and the mathematical model to be used in the solution of the } \\
\text { problem are discussed for the first time in the literature. The developed model was tested on } \\
\text { the problem sets created by taking into account the data of the province under investigation. } \\
\text { Analysis results showed that the developed model can reach optimal solutions in small and } \\
\text { medium-sized problems, and as the size of the problem increases, it does not reach the } \\
\text { optimal solution in a short time, but it can produce appropriate solutions. }\end{array}$ \\
\hline
\end{tabular}

\section{Introduction}

It is very difficult to predict the devastating damage caused by disasters. For this reason, it is necessary to take necessary precautions before, during, and after the disaster, to improve conditions and to plan for logistics. This makes it necessary to understand the concepts of disaster management and amnesty logistics thoroughly and to increase the importance of the studies on these concepts.

Disasters are divided into two groups as natural and human in terms of their occurrence [1]. While natural disasters occur as a result of nature's own actions, human disasters occur as a result of the increase of people's effects on nature. Earthquakes, storms, floods, hurricanes, avalanches and landslides are important natural disasters.
Outbreaks, fires and transport accidents appear as human disasters. Earthquakes, like all other disasters, are situations that are very difficult to predict and result in loss of life and property. Taking necessary precautions before an earthquake can be life-saving in case of an earthquake. Likewise, it is known that if the instructions to be applied during an earthquake are followed, the survival probability of people increases. However, even if all these measures are taken and implemented, there may be structures that collapsed after a severe earthquake with a very high intensity and earthquake survivors struggling to survive. In such cases, it is vital to benefit from search and rescue and health services as quickly as possible.

The effective and rapid execution of search and rescue activities is possible by scanning the area where the

\footnotetext{
* Corresponding Author: Lutfu S. Sua

E-mail address: sua_1@auca.kg
}

Received: 5 March 2021; Revised: 25 March 2021; Accepted: 29 March 2021

https://doi.org/10.52547/crpase.7.2.2333
Please cite this article as: Z. Mahmat, L. S. Sua, F. Balo, Mathematical Modeling in Disaster Logistics: Multi-Depot Vehicle Routing Problem, Computational Research Progress in Applied Science \& Engineering, CRPASE: Transactions of Industrial Engineering 7 (2021) $1-9$, Article ID: 2333.


earthquake occurred in a short time and determining the damage. In the earthquake that occurred on Friday, January 24, 2020 at 20.55 in Elazig, images were taken in a short period of 25 minutes with Unmanned Aerial Vehicles (UAV) and Manned Reconnaissance Aircraft (MRA) and transferred to the Gendarmerie Command Center. In addition, the MRA and UAVs used to scan 275 different points in 3 hours, making a very important contribution to search and rescue efforts. Later, the dead and wounded were reached through search and rescue efforts from earthquake debris.

One of the most important issues after the search and rescue efforts is the treatment of the injured in the shortest time and then transfer to the nearest hospitals in the shortest time. This research involves scanning the city center with UAVs and routing the restricted number of ambulances to the assigned hospitals in the minimum duration. In the first part of the study, the problem of UAV routing was focused on in order to scan for debris and start search and rescue studies quickly and efficiently. The mathematical model of the cluster coverage problem was used while routing the UAV. In the second part, the ambulance routing problem was discussed and a new mathematical model was developed by using the multi-warehouse vehicle routing problem in the literature in order to provide the fastest treatment for the injured people who were reached through search and rescue studies. The developed model was then tested on different scenarios with the help of the GAMS program. While developing the scenarios, the data is created by visiting the wreckage sites of Elazig province, which is on the earthquake zone and was shaken by a magnitude of 6.8 earthquake that caused 41 dead, 1466 injured and major damage on January 24, 2019.

In the first part of the study, the purpose and scope are specified, and information about the studies in the literature on the subject is provided. In the second part, theoretical foundations such as disaster, disaster management, disaster logistics, and disaster types are mentioned. In the third part, the details of the problem dealt with in the study are expressed and the mathematical models developed for the problem are introduced. In the fourth chapter, the research findings were shared, while the general evaluation of the study and information about future studies are presented in the last chapter.

\subsection{Purpose and Scope of the Study}

Turkey is located in the world's most earthquake generating Alps-Himalayan seismic zone. This is the main cause of earthquakes in the country. Since earthquakes are not known in advance, people can only take the necessary precautions before an earthquake and the things that should be applied during an earthquake with the best possibility. Even if all kinds of precautions are taken, the destructiveness and intensity of earthquakes can be very high. In other words, it makes debris scanning, logistics and health services much more important after an earthquake. For the stated reasons, $\mathrm{UAV}$ and ambulance routing have been chosen as the subject of this research. The scope of this study consists of the neighborhoods of the central district of Elazig province.

\section{Scientific Foundations}

Disasters are caused by nature and human beings in terms of their types and cause loss of life and property. Regardless of the cause and source, it is necessary to minimize such losses. This includes disaster management measures to be implemented. At the same time, as disasters cannot be prevented, post-disaster logistics activities are also important in preventing significant casualties.

\section{1. Disaster Management and Disaster Logistics}

Disaster management involves the tasks carried out in order to make people aware of the natural conditions that occur in the region they live in, to recognize the reasons for these situations in detail, and to help them not to be affected in the face of repetition of such situations [2].

In order for disaster management to be successful, it should aim at minimizing the damage rather than optimizing the events [3]. Figure 1 presents the phases in disaster management.

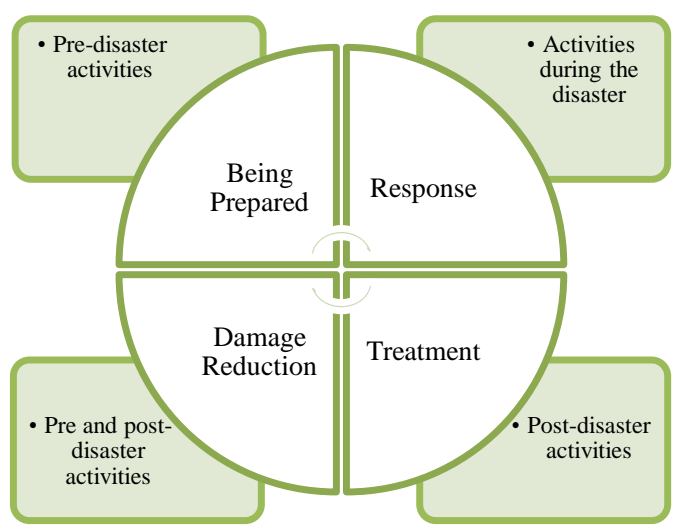

Figure 1. Phases in Disaster Management

One of the most important issues in disaster management is pre-disaster planning and disaster logistics, which will turn into a post-disaster practice [4].

Disaster logistics is expressed as the collection of studies on the transportation of first aid materials, equipment, food and beverage and search and rescue teams that may need all kinds to very scattered points, removing the injured from the scene very quickly and taking them to health institutions for necessary treatment [5].

\section{Methods}

In this study, Elazig province, which is located in an earthquake zone, is taken into consideration. The first thing to do right after a severe and destructive earthquake is to scan the area where the earthquake occurred and to determine the places of debris. After the earthquake in the city on January 24, 2020, debris scanning was carried out with IKU and UAVs and very significant benefits were achieved. In this study, it is aimed to evaluate the UAVs in the cluster coverage problem and find the required number of UAVs. Using the mathematical model of the cluster coverage problem, the number of UAVs required to be used in screening was determined by evaluating the UAVs within 38 neighborhoods of the central district of the province. Then, 
taking into account the characteristics of 6 hospitals and multiple ambulance types in the central district of the province, the problem of assigning the injured to the hospital and routing the ambulances were discussed. Details on the related problems are given in the sections below.

\subsection{Coverage Problems}

Coverage models are mostly used for location problems. While there are a certain number of customers (target/city/demand points) in the coverage models, it is aimed to determine the number of facilities (supply points) that will meet the needs of all of them in a way that will have the least cost or the largest coverage area.

Some of the coverage problems are given below [6]:

- Cluster Coverage Problem [7, 8, 9].

- Highest Space Coverage Problem [10]

- Double Coverage Problem [11]

- Reserve Coverage [11]

- Reliable Coverage Problem

\subsubsection{Cluster Coverage Problem}

Cluster coverage is a type of model developed to respond to all demand points of the supply points planned to be established with the least cost. The most common use of cluster coverage models is to determine the number of emergency aid stations and distribution centers in case of disasters.

Cluster coverage Model is provided below [7];

The written model is given for $\mathrm{T}$ demand points and $\mathrm{S}$ facility points.

\section{Indices:}

$i=$ Index indicating the demand points $i=1,2,3$, ....,T

$j=$ Index indicating facility points $\mathrm{j}=1,2,3, \ldots . ., \mathrm{S}$

Parameters:

$\mathrm{a}_{\mathrm{ij}}=$

$\{1$ if facility $j$ meets the demand of demand $i$

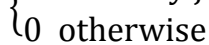

$\mathrm{M}_{\mathrm{j}}=$ fixed of facility $\mathrm{j}$

Decision Variables:

$\mathrm{x}_{\mathrm{j}}=\left\{\begin{array}{l}1 \text { if facility is is to be established at } \mathrm{j} \\ 0 \text { if not }\end{array}\right.$

Objective Function:

$\operatorname{Min} \sum_{j=1}^{S} M_{j} * x_{j}$

Constraints:

$\sum_{j=1}^{S} a_{i j} * x_{j} \geq 1$

$\mathrm{x}_{\mathrm{j}} \in\{0,1\} \quad \forall \mathrm{j}$

If the costs are the same for each facility to be opened, the objective function is:

$$
\operatorname{Min} \sum_{j=1}^{S} x_{j}
$$

While the aim in Eq. (1) is to minimize the total cost, the aim is to minimize the number of facilities to be opened in Eq. (4) since facility opening costs are equal. Eq. (2) is the constraint that cuts the inclusion of each demand point of the facilities to be opened. Finally, Eq. (3) is the constraint of the decision variable to be an integer.

\subsubsection{Cluster Coverage Model for Determining the Number of $U A V s$}

Considering the mathematical model in the previous section, the following mathematical model has been established to determine the number of UAVs to be used in screening activities after the earthquake.

\section{Indices:}

$\mathrm{i}=$ Index indicating the neighborhood $\mathrm{i}=1,2$,

$3, \ldots ., \mathrm{T}$

$\mathrm{j}=$ Index indicating the neighborhood to be centered for UAVs $\mathrm{j}=1,2,3, \ldots . ., \mathrm{S}$

Parameters:

$\mathrm{a}_{\mathrm{ij}}=\left\{\begin{array}{c}1 \text { if } j \text { is covering neightborhood } i \\ 0 \text { otherwise }\end{array}\right.$

Decision Variables:

$\mathrm{x}_{\mathrm{j}}=\left\{\begin{array}{l}1 \mathrm{j} \text { point center neighborhood is chosen } \\ 0 \text { otherwise }\end{array}\right.$

Objective Function:

$\operatorname{Min} \sum_{j=1}^{S} x_{j}$

Constraints:

$\sum_{j=1}^{S} a_{i j} * x_{j} \geq 1$

$\mathrm{x}_{\mathrm{j}} \in\{0,1\}$

The aim in Eq. (5) is to minimize the total cost. Eq. (6) is the constraint that cuts the inclusion of each demand point of the facilities to be opened. Finally, Eq. (7) is the constraint of the decision variable to be an integer.

Using this model in the implementation study in Section 4 , it was intended to determine the ideal number of UAVs to be used in screening activity for the province.

\subsection{Vehicle Routing Problem}

It is a much more difficult problem in terms of VRP solution with more constraints and multiple tools than the Traveling Salesman Problem (TSP). Again, the fact that VRP problems are static or dynamic does not prevent them from being included in the NP-Hard group [12]. Although it varies in terms of VRP constraints, 3 areas emerge [13]. These are: 
1) Restrictions on the vehicles planned to be used

- Capacity constraints of vehicles in terms of weight or volume

- Constraints on total vehicle time

○ Restrictions on legal working hours of vehicle drivers

2) Restrictions on existing customers

- Each customer has one or more product demand constraints

- Limited time frames constraints for distribution of product claims

3) Other constraints

- Number of tours of the vehicles is more than one (the same vehicle returns to the warehouse on the same day and leaves for another road) restrictions

- Tours exceeding one day in terms of length

- The number of depots to be used is more than one

It was determined that the problem dealt with in the scope of this study is related to the Multi-Depot Vehicle Routing Problem (MD-VRP) and the information about the MD-VRP is stated in the next section.

\subsubsection{Multi-Depot Vehicle Routing Problem}

In general, MDVRP is a type of problem that deals with providing service to many customers from more than one warehouse in the shortest possible time and cost and determining vehicle routes. Multi-depot vehicle routing problems are used in combinatorial optimization problems in which a number of vehicles serve the clients. The vehicles leave the depot/station, serve clients in the network, and return to the depot/station after completion of their routes. Thus, among many applications, public transportation [14], urban traffic planning [15], and supply chain distribution networks can be mentioned. Yilmaz made the modeling of the multi-depot vehicle routing problem with the ant colony algorithm and proposed a solution [16]. Yildiz discussed the problems of vehicle routing charts in the transportation sector [17]. Onder, discussed the bread distribution of Istanbul Public Bakery Factories as a multi-depot vehicle routing problem [18]. In his study, Ozer benefited from the problem of multi-depot vehicle routing to take liver transplantation to transplant centers in a short time [19]. Kiziloglu investigated the stochastic multi-depot vehicle routing problem with heuristic solutions under the chance constraint approach [20]. Sadatizamanabad used the multidepot vehicle routing problem in supply chain networks and aimed to protect critical facilities [21]. Ozen developed the mathematical model of the open-ended multi-depot vehicle routing problem for the feeder bus network design [22].

In this problem, the assignment of the vehicles to the depot, the assignment of the customers to the vehicles and the customer demands not exceeding the vehicle capacities appear as important constraints. In line with these constraints, it is important to decide which customers should be served from which depot and with which vehicle. Within the scope of the subject dealt with in this study, it is important to determine which injured people will be served from which hospital and by which ambulance. In the ambulance routing problem addressed here, hospitals are considered as depots, the wounded as customers and ambulances as vehicles.

To solve the problem discussed in this study, following mathematical model developed by Mirabi [23] for the MDVRP was benefited from:

Sets;
I: Depots
J: Customers
$\mathrm{K}$ : Vehicles
Parameters;
$\mathrm{N}$ : Total number of customers
$\mathrm{c}_{\mathrm{ij}}=$ distance between $\mathrm{i}$ and $\mathrm{j}$ points $\mathrm{i}, \mathrm{j} \in \mathrm{I} \mathrm{U} \mathrm{J}$
$\mathrm{v}_{\mathrm{i}}=$ capacity of the depot $\mathrm{I}, \mathrm{i} \in \mathrm{EI}$
$\mathrm{d}_{\mathrm{j}}=$ demand from customer $\mathrm{j}, \mathrm{j} \in \mathbf{J}$
$\mathrm{q}_{\mathrm{k}}=$ capacity of vehicle $\mathrm{k}, \mathrm{k} \in \mathrm{K}$

\section{Decision variables;}

$\mathrm{x}_{\mathrm{ijk}}=$

$\{1$, if using vehicle $\mathrm{k}$ from point $\mathrm{i}$ to point $\mathrm{j}$

$\{0$, otherwise

$\mathrm{z}_{\mathrm{ij}}= \begin{cases}1, & \text { if customer } \mathrm{j} \text { is assigned to depot } \\ 0, & \text { otherwise }\end{cases}$

$\mathrm{U}_{\mathrm{lk}}=$ dummy variable, which is the sub-tour

elimination constraint on vehicle/route $\mathrm{k}$

Mathematical Model;

$\operatorname{Min} Z=\sum_{i \in I U J} \sum_{j \in I U J} \sum_{k \in K} x_{i j k} c_{i j}$

$\sum_{\mathrm{k} \in \mathrm{K}} \sum_{\mathrm{i} \in \mathrm{IU} J} \mathrm{x}_{\mathrm{ijk}}=1$

$\mathrm{U}_{\mathrm{lk}}-\mathrm{U}_{\mathrm{jk}}+\mathrm{Nx}_{\mathrm{ljk}} \leq \mathrm{N}-1$

$\sum_{j \in I U J} x_{i j k}-\sum_{j \in I U J} x_{j i k}=0$

$\sum_{\mathrm{k} \in \mathrm{K}} \sum_{\mathrm{i} \in \mathrm{IUJ}} \mathrm{x}_{\mathrm{ijk}} \leq 1$

$\sum^{\mathrm{k} \in \mathrm{K}} \sum_{\mathrm{i}}$

$\sum_{i \in I U J} \sum_{j \in J} d_{j} x_{i j k} \leq q_{k}$

$\sum_{\mathrm{j} \in \mathrm{J}} \mathrm{d}_{\mathrm{j}} \mathrm{z}_{\mathrm{ij}} \leq \mathrm{v}_{\mathrm{i}}$

$-z_{i j}+\sum_{u \in I U J}\left(x_{i u k}+x_{u j k}\right) \leq 1$

$\mathrm{x}_{\mathrm{ijk}} \in\{0,1\}$

$\mathrm{z}_{\mathrm{ij}} \in\{0,1\}$

$U_{l k} \geq 0$

The objective function of the model is to minimize the distance traveled (Eq. (8)). Eq. (9) refers to the assignment of each customer to a single route. Eq. (10) expresses the sub-route elimination. Eq. (11) means that each node in the routes has a single entry and exit. Eq. (12) means that each vehicle is dispatched from a single depot. Eq. (13) means that the demands of the customers on each route do not exceed the capacities of the vehicles on the routes. Eq. (14) means that each customer demand should not exceed the capacity of the depot to which it is assigned. The constraint numbered Eq. (15) means that each customer is on the route of the depot to which it is assigned. Eqs. (16), (17), and (18) are the sign constraints for the decision variables. 


\subsubsection{Mathematical Model Developed for Ambulance Routing Problem}

Based on the mathematical model that Mirabi [23] has developed for the multi-depot vehicle routing problem, the mathematical model that has been developed within this research is presented in this section. This new model is the first major contribution of this research to the related literature. Another contribution is the introduction of a new type of problem called ambulance routing problem which has been developed based on this problem. It has been discovered that there is no study on the ambulance routing problem in the literature. For this reason, it has been determined that this study is different from other studies in the literature in terms of both the problem and the proposed mathematical model.

Ambulance routing problem covered within the context of this study aims to deliver the injured ones to the nearby hospitals in the most effective manner given the existing constraints. However, when ambulance capacities are considered, it is important that ambulances make more than one trip and deliver the other injured people to hospitals. At the same time, it is considered that ambulances will transport the injured to different hospitals in case the hospital capacities are over. Figure 2 shows the hospitals, ambulances, and casualty locations in some parts of the city.

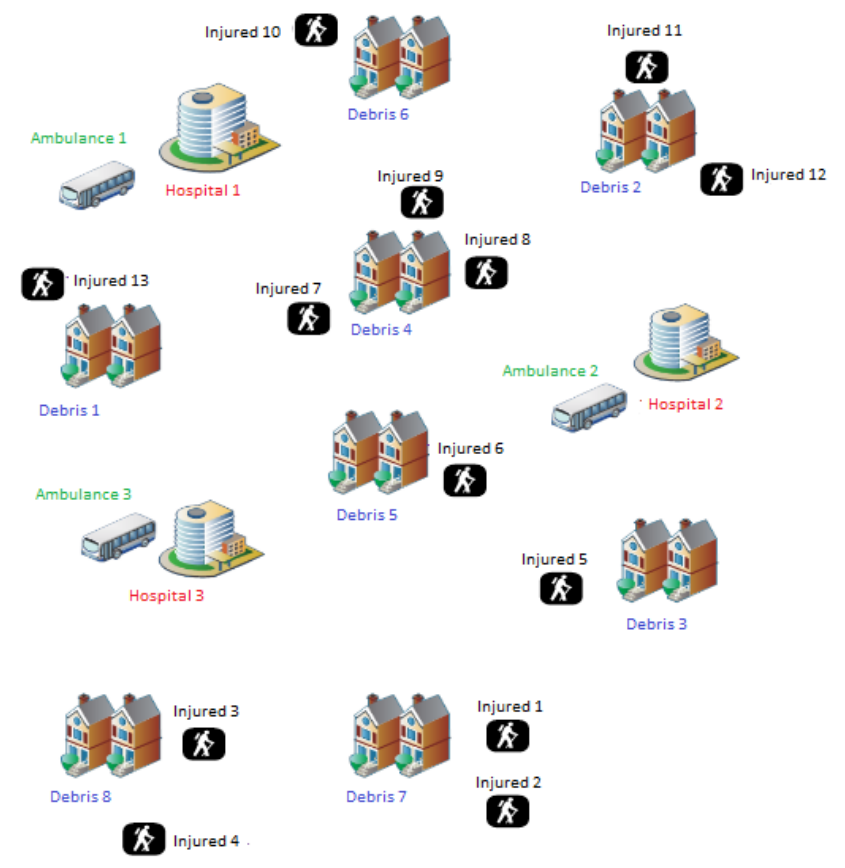

Figure 2. An example solution to the problem

In the sample problem presented in Figure 2, it can be observed that there are 3 hospitals, 3 ambulances and 13 injured. Here, it is assumed that each ambulance can carry a maximum of 2 patients at once and capacities for each hospital are defined. According to the solution presented in this figure, " 1 st ambulance has 2 trips", " 2 nd ambulance has 3 trips" and " 3 rd ambulance has 2 trips". The 1 st ambulance carries the 7th and 10th individuals on the first trip, and the $13^{\text {th }}$ on the $2^{\text {nd }}$ trip. The second ambulance carries the 5 th and 6 th individuals on the first trip, the $11^{\text {th }}$ and $12^{\text {th }}$ ones on the $2^{\text {nd }}$ trip, and the $8^{\text {th }}$ and $9^{\text {th }}$ on the $3^{\text {rd }}$ trip. Finally, the $3^{\text {rd }}$ ambulance carries the 3rd and 4th injured people on the first trip, and the $1^{\text {st }}$ and $2^{\text {nd }}$ on the 2 nd trip. Ambulance and hospital capacities were also taken into consideration while performing the solution.

The problem in Figure 2 includes many constraints, parameters, and assumptions in it. The constraints, parameters, and assumptions considered in this study are specified below:

- Every patient must be transported to a hospital.

- Routing should be carried out without exceeding the hospital and ambulance capacities.

- Ambulance capacities were assumed to be equal (1-2-3 or 4).

- Ambulances can make more than one trip.

- It is assumed that it is possible for an ambulance to transport the injured to the other hospitals other than the hospital to which it belongs, but it arrives at the next injury location after stopping at the hospital to which it will transport in the first place and taking the relevant equipment. For example, the first ambulance departing from the first hospital can take the 5th and 7th patients, and after returning to the first hospital, they can go on a second trip to transport the injured in the system to the nearest hospital. In this case, the injured people can go to the other hospital (for example the second hospital) first to get the relevant equipment, then reach the relevant injury locations (for example the 3rd and 8th injured) and return to the second hospital. In this case, the total mission route for the first ambulance is as follows: First trip: 1st hospital- 5th injured, 7th injured -1st hospital. Second trip: 2nd hospital- 3rd injured-8th injured-2nd hospital. In this way, it was aimed to create a full tour for ambulances and to terminate their duties in the hospitals they started. In this case, it is aimed to reflect the hospital changes of the ambulances to the objective function.

Information on the mathematical model developed under these assumptions is given below:

Index sets;
I: Hospitals
$\mathrm{J}$ : Injuries
$\mathrm{K}$ : Ambulances
M: Trips

Parameters;

$\mathrm{N}$ : Total number of injuries

$\mathrm{c}_{\mathrm{ij}}=$ distance between $\mathrm{i}$ and $\mathrm{j}$ points $\mathrm{i}, \mathrm{j} \in \mathrm{I} \mathrm{U} \mathrm{J}$

$\mathrm{v}_{\mathrm{i}}=$ capacity of hospital $\mathrm{i}, \mathrm{i} \in \mathrm{CI}$

$\mathrm{d}_{\mathrm{j}}=$ demand of injury $\mathrm{j}, \mathrm{j} \in \mathrm{J}$

$\mathrm{q}_{\mathrm{k}}=$ capacity of ambulance $\mathrm{k}, \mathrm{k} \in \mathrm{K}$

$b_{m}=$ cost of trip $m, m \in M$

Decision variables;

$\mathrm{x}_{\mathrm{mijk}}=\left\{\begin{array}{l}1, \text { if ambulance } \mathrm{k} \text { is used from point } \mathrm{i} \text { to } \mathrm{j} \text { with } \\ \text { trip } \mathrm{m}\end{array}\right.$
$\mathrm{i}, \mathrm{j} \in \mathrm{IUJ}$
$\mathrm{z}_{\mathrm{mij}}= \begin{cases}1, & \text { otherwise } \mathrm{j} \text { is transported to hospital i with trip } \mathrm{m} \\ 0, & \text { otherwise }\end{cases}$ 
$\mathrm{p}_{\mathrm{mijk}}=$

$\{1$, if ambulance $\mathrm{k}$ goes to hospital $\mathrm{j}$ from $\mathrm{i}$ with trip $\mathrm{m}$

$\{0$, otherwise

$\mathrm{U}_{\mathrm{mlk}}=$ dummy variable of sub-tour elimination constraint at

$\mathrm{k}$ ambulance/route

$\mathrm{h}_{\mathrm{m}}=$ variable showing the availability of trip $\mathrm{m}$

$$
\begin{aligned}
& \text { Mathematical Model; } \\
& \operatorname{Min} \mathrm{Z}=\sum_{m \in M} \sum_{\mathrm{i} \in \mathrm{IUU}} \sum_{\mathrm{j} \in \mathrm{IUJ}} \sum_{\mathrm{k} \in \mathrm{K}} \mathrm{x}_{\mathrm{mijk}} \mathrm{c}_{\mathrm{ij}} \\
& +\sum_{m \in M} \sum_{\mathrm{i} \in \mathrm{I}} \sum_{\mathrm{j} \in \mathrm{I}} \sum_{\mathrm{k} \in \mathrm{K}} \mathrm{p}_{\mathrm{mijk}} \mathrm{c}_{\mathrm{ij}} \\
& +\sum_{\mathrm{m} \in \mathrm{M}} \mathrm{h}_{\mathrm{m}} \mathrm{b}_{\mathrm{m}} \\
& \sum_{m \in M} \sum_{\mathrm{k} \in \mathrm{K}} \sum_{\mathrm{i} \in \mathrm{IUU}} \mathrm{x}_{\mathrm{mijk}}=1 \\
& \mathrm{U}_{\mathrm{mlk}}-\mathrm{U}_{\mathrm{mjk}}+\mathrm{Nx}_{\mathrm{mljk}} \leq \mathrm{N}-1 \\
& \sum_{j \in I U J} x_{m i j k}-\sum_{j \in I U J} x_{m j i k}=0 \\
& \sum_{\mathrm{k} \in \mathrm{K}} \sum_{\mathrm{i} \in \mathrm{IUJ}} \mathrm{x}_{\mathrm{mijk}} \leq 1 \\
& \sum_{i \in I U J} \sum_{j \in J} d_{j} x_{m i j k} \leq q_{k} \\
& \sum_{j \in J} d_{j} z_{m i j} \leq v_{i} \\
& -\mathrm{z}_{\mathrm{mij}}+\sum_{\mathrm{u} \in \mathrm{IUJ}}\left(\mathrm{x}_{\text {miuk }}+\mathrm{x}_{\text {mujk }}\right) \leq 1 \\
& -1+\sum_{\mathrm{j} \in \mathrm{J}} \mathrm{x}_{\mathrm{mijk}}+\sum_{\mathrm{j} \in \mathrm{J}} \mathrm{x}_{\mathrm{wtjk}}-\sum_{o \in M} \sum_{j \in J} x_{o i j k} \\
& \leq \mathrm{p}_{\text {mitk }}
\end{aligned}
$$

$\forall \mathrm{i} \in \mathrm{I}, \mathrm{t} \in \mathrm{I}, \mathrm{k} \in \mathrm{K},(\mathrm{m}, \mathrm{w}, \mathrm{o}) \in \mathrm{M}, \quad i \neq t, m>o>$

$w, m>1$

$\mathrm{x}_{\mathrm{mijk}}=0$

$\sum_{\mathrm{i} \in \mathrm{I}} \sum_{\mathrm{j} \in \mathrm{J}} \mathrm{z}_{\mathrm{mij}}=\mathrm{h}_{\mathrm{m}}$

$\sum_{\mathrm{i} \in \mathrm{I}} \sum_{\mathrm{j} \in \mathrm{J}} \mathrm{z}_{\mathrm{mij}} * 1000 \geq \sum_{\mathrm{i} \in \mathrm{I}} \sum_{\mathrm{j} \in \mathrm{J}} \mathrm{z}_{(\mathrm{m}+1) \mathrm{ij}}$

$\mathrm{x}_{\mathrm{mijk}} \in\{0,1\}$

$\mathrm{z}_{\mathrm{mij}} \in\{0,1\}$

$U_{m l k} \geq 0$

In the objective function of the model (Equation 19), the total duty time, the cost of ambulances going to distant hospitals, and the costs arising from the additional trips were tried to be minimized. Equation (20) implies assigning a single route for each injured. Equation (21) represents the sub-tour elimination. Equation (22) means that each node in the routes has a single entry and exit. Equation (23) means that each ambulance leaves a single hospital. Equation (24) means that the demands of the injured on each route do not exceed the capacities of the ambulances on the routes. Equation (25) means that each injured demand should not exceed the capacity of the hospital to which it is assigned. Equation (26) means that each injured person is on the route of the hospital to which they are assigned. Eq. (27) ensures that ambulances are directed to the same and nearest hospital, if possible. Eq. (28) ensures that the transfer between hospitals is not assigned to each other at the relevant time. Eq. (29) allows the trips to be activated gradually. Equation (30) ensures the assignment of injured people to be transported in the initial trips to a large number of hospitals. Eqs. (31), (32), and (33) are the constraints limiting the signs of the decision variables.

In the next section, the developed model is tested on various scenarios and its results are analyzed.

\section{Research Findings}

In this study, the central district of Yalova province has been taken into account and the debris scanning and the most efficient transportation of the injured from under the debris to the hospitals are emphasized, based on the previous earthquake. Two different mathematical models (Sections 3.1.1. and 3.2.1.) have been developed for debris scanning and rescuing the injured from under debris and transferring them to the hospitals. The developed model was tested by taking into account the data in the district and the information regarding the implementation study is given in the following sections.

\subsection{Determining the Ideal Number of UAVs}

Within the scope of the thesis, the cluster coverage problem for 14 districts of Yalova province was addressed and the required number of UAVs was tried to be determined. The purpose of cluster coverage problems is to serve the maximum number of areas with the minimum number of facilities. Based on this idea, UAVs are considered as facilities and it is aimed to find the required number. In determining the required number of UAVs, the distances between the neighborhoods were calculated using the Google Maps application. Relevant distances represent the value in minutes of the distance traveled by vehicles. While solving the problem, assuming that the UAVs scan distances of 5 minutes, the number of UAVs required for scanning was aimed to be found with the mathematical model in Section 3.1.2.

As a result of solving the relevant model with the Gams software, it was determined that it requires 5 UAVs for a 5 minute scanning distance. Considering the need for a more detailed scanning after an earthquake, 5 UAVs are assumed to be needed in developing data sets in the application phase of the ambulance routing problem and the injured individuals are distributed to the districts considering these clusters. The district clusters that occur when 7 UAVs are used are given in Table 1.

Table 1. District Clusters Obtained as a Result of Solving the Cluster Inclusion Problem

\begin{tabular}{llll}
\hline \multicolumn{2}{l}{ Cluster Number Central Clusters } & District Numbers Covered \\
\hline 1 & (A) & 1.Gaziosmanpaşa & $1,3,13$ \\
2 & (B) & 2.Fevziçakmak & 2,14 \\
3 & (C) & 9.Bahçelievler & $4,9,11$ \\
4 & (D) & 10.Seyrantepe & $5,6,7,8,10$ \\
5 & (E) & 12.Paşakent & 12 \\
\hline
\end{tabular}


In the next section, data sets were prepared based on the obtained sets and the mathematical model developed for the ambulance routing problem was tested.

\subsection{Routing Ambulances}

While routing the ambulances, 5 district clusters were obtained by applying the mathematical model in section 3.1.2 for 14 districts of Yalova province. Based on these district clusters, the mathematical model in section 3.2.2 has been tested. The parameters addressed during the model trial are:

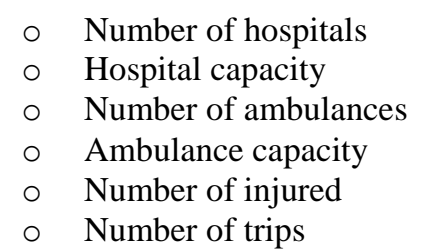

Information on these parameters is provided below.

Number of Injured: The number of injuries in the problem sets varies between 10 and 40, and as the number of injured increases, the time to solve the problem and its reaction to the results are tried to be determined. In addition, the injuries are distributed randomly to different locations in the city center and real geographical data of the region is used while determining the locations of the injured people. The casualties were randomly allocated to the districts in the clusters determined during the cluster coverage stage, and the condition that each cluster should have at least one injured was added. For the scenario of UAVs on the 5-minute scan, it is assumed that the injured ones are distributed to the districts within the 5 clusters determined under the assumption of $5 \mathrm{UAVs}$ are required. The injuries distributed randomly to clusters and districts under 12 trials are shown in Table 2.

Number of Hospitals: Three hospitals were established considering the hospitals in the province. While creating the relevant distance matrices in the problems, the actual locations of the above hospitals were taken into account and the actual distances between these locations and the injuries were added to the path matrix. In addition, it was assumed that the number of hospitals in the problems varied between 1 and 3, thus it was aimed to determine the dynamic response of the problem to the increase in the number of hospitals.

Hospital Capacity: While determining the total hospital capacity, it was considered to be more than the total number of injured and the values were given randomly. The total hospital capacity is shared among the relevant hospitals at different rates. For example, in the related problem, if it is assumed that there are 2 hospitals and the total hospital capacity is determined to be 30 , the capacity of one hospital may be 10 and the other 20 . Or the capacity of both could be 15. The number of hospitals used under 16 trial studies and their total capacities is shown in Table 3 while the distribution of the total capacity to the hospitals is shown in Table 4.
Table 2. Random distribution of the injured by the district clusters

\begin{tabular}{|c|c|}
\hline Trial & Cluster + District (\# of Injured) \\
\hline 1 & $\begin{array}{l}10 \quad \mathrm{~A} 1(1)-\mathrm{A} 3(1)-\mathrm{B} 2(1)-\mathrm{C} 4(1)-\mathrm{C} 9(1)-\mathrm{D} 5(1)- \\
\mathrm{D} 6(1)-\mathrm{D} 7(1)-\mathrm{D} 8(1)-\mathrm{E} 12(1)\end{array}$ \\
\hline 2 & $\begin{array}{l}10 \quad \mathrm{~A} 1(1)-\mathrm{A} 3(1)-\mathrm{A} 13(1)-\mathrm{B} 2(1)-\mathrm{B} 14(1)-\mathrm{C} 9(1)- \\
\mathrm{C} 11(1)-\mathrm{D} 8(1)-\mathrm{D} 10(1)-\mathrm{E} 12(1)\end{array}$ \\
\hline 3 & $\begin{array}{l}10 \mathrm{~A} 1(1)-\mathrm{A} 3(1)-\mathrm{B} 2(1)-\mathrm{C} 4(1)-\mathrm{C} 9(1)-\mathrm{C} 11(1)- \\
\mathrm{D} 6(1)-\mathrm{D} 7(1)-\mathrm{D} 10(1)-\mathrm{E} 12(1)\end{array}$ \\
\hline 4 & $\begin{array}{l}10 \quad \mathrm{~A} 1(1)-\mathrm{A} 3(1)-\mathrm{A} 13(1)-\mathrm{B} 2(1)-\mathrm{C} 4(4)-\mathrm{D} 5(1)- \\
\mathrm{E} 12(1)\end{array}$ \\
\hline 5 & $\mathrm{~A} 1(4)-\mathrm{B} 2(4)-\mathrm{C} 4(4)-\mathrm{D} 5(4)-\mathrm{E} 12(4)$ \\
\hline 6 & $\begin{array}{l}20 \quad \mathrm{~A} 3(4)-\mathrm{A} 13(4)-\mathrm{B} 2(2)-\mathrm{B} 14(2)-\mathrm{C} 9(1)-\mathrm{C} 11(1)- \\
\mathrm{D} 6(1)-\mathrm{D} 7(1)-\mathrm{E} 12(4)\end{array}$ \\
\hline 7 & $\begin{array}{l}20 \quad \mathrm{~A} 1(1)-\mathrm{A} 3(1)-\mathrm{A} 13(1)-\mathrm{B} 2(1)-\mathrm{B} 14(1)-\mathrm{C} 4(3)- \\
\mathrm{D} 8(3)-\mathrm{D} 10(3)-\mathrm{E} 12(6)\end{array}$ \\
\hline 8 & $\begin{array}{l}20 \quad \mathrm{~A} 1(1)-\mathrm{A} 3(1)-\mathrm{A} 13(1)-\mathrm{B} 2(1)-\mathrm{B} 14(4)-\mathrm{C} 11(4)- \\
\mathrm{D} 5(1)-\mathrm{D} 6(1)-\mathrm{D} 7(1)-\mathrm{D} 8(1)-\mathrm{E} 12(4)\end{array}$ \\
\hline 9 & $\begin{array}{l}30 \quad \mathrm{~A} 13(5)-\mathrm{B} 2(3)-\mathrm{B} 14(3)-\mathrm{C} 9(6)-\mathrm{D} 5(4)-\mathrm{D} 10(4)- \\
\mathrm{E} 12(5)\end{array}$ \\
\hline 10 & $\begin{array}{l}30 \quad \mathrm{~A} 1(2)-\mathrm{A} 13(2)-\mathrm{B} 2(4)-\mathrm{C} 9(6)-\mathrm{D} 6(4)-\mathrm{D} 8(4)- \\
\mathrm{D} 10(4)-\mathrm{E} 12(4)\end{array}$ \\
\hline 11 & $\begin{array}{l}30 \quad \mathrm{~A} 1(3)-\mathrm{A} 3(3)-\mathrm{A} 13(3)-\mathrm{B} 2(1)-\mathrm{B} 14(2)-\mathrm{C} 4(3)- \\
\mathrm{C} 9(3)-\mathrm{C} 11(3)-\mathrm{D} 5(1)-\mathrm{D} 6(1)-\mathrm{D} 7(1)-\mathrm{D} 8(1)-\mathrm{D} 10(2)-\mathrm{E} 12(3)\end{array}$ \\
\hline 12 & $\begin{array}{l}30 \quad \mathrm{~A} 13(4)-\mathrm{B} 2(4)-\mathrm{B} 14(4)-\mathrm{C} 4(4)-\mathrm{D} 5(1)-\mathrm{D} 6(1)- \\
\mathrm{D} 7(1)-\mathrm{D} 8(1)-\mathrm{D} 10(4)-\mathrm{E} 12(6)\end{array}$ \\
\hline 13 & $\begin{array}{l}40 \quad \mathrm{~A} 3(6)-\mathrm{B} 14(5)-\mathrm{C} 9(6)-\mathrm{C} 11(6)-\mathrm{D} 8(6)-\mathrm{D} 10(6)- \\
\mathrm{E} 12(6)\end{array}$ \\
\hline 14 & $\begin{array}{l}40 \quad \mathrm{~A} 1(5)-\mathrm{A} 3(5)-\mathrm{B} 2(4)-\mathrm{B} 14(6)-\mathrm{C} 4(6)-\mathrm{C} 9(4)- \\
\mathrm{D} 5(4)-\mathrm{D} 6(4)-\mathrm{E} 12(2)\end{array}$ \\
\hline 15 & $\begin{array}{l}40 \quad \mathrm{~A} 13(6)-\mathrm{B} 14(6)-\mathrm{C} 11(5)-\mathrm{D} 5(6)-\mathrm{D} 6(6)-\mathrm{D} 7(6) \\
\mathrm{E} 12(5)\end{array}$ \\
\hline 16 & $\begin{array}{l}40 \quad \mathrm{~A} 1(4)-\mathrm{A} 3(4)-\mathrm{A} 13(4)-\mathrm{B} 2(4)-\mathrm{B} 14(4)-\mathrm{C} 4(4)- \\
\mathrm{C} 9(4)-\mathrm{C} 11(4)-\mathrm{D} 5(1)-\mathrm{D} 6(1)-\mathrm{D} 7(1)-\mathrm{D} 8(1)-\mathrm{D} 10(1)-\mathrm{E} 12(3)\end{array}$ \\
\hline
\end{tabular}

Table 3. Number of hospitals and their total capacities

\begin{tabular}{lcc}
\hline Trial & Number of Hospitals & Total Hospital Capacity \\
\hline 1 & 1 & 15 \\
2 & 1 & 15 \\
3 & 1 & 15 \\
4 & 1 & 15 \\
5 & 2 & 30 \\
6 & 2 & 30 \\
7 & 2 & 30 \\
8 & 2 & 30 \\
9 & 3 & 45 \\
10 & 3 & 45 \\
11 & 3 & 45 \\
12 & 3 & 45 \\
13 & 3 & 60 \\
14 & 3 & 60 \\
15 & 3 & 60 \\
16 & 3 & 60 \\
\hline
\end{tabular}

Number of Ambulances: Within the scope of the study, the number of ambulances varied between 2 and 10, thus the effect of the increase in the number of ambulances on the solution of the problem was tried to be determined. Ambulance starting points are assumed to be at the respective hospitals. The number of ambulances allocated to each hospital within the related problem was determined randomly.

Ambulance Capacity: During the research, it was noted that ambulances with capacity of four are available and being actively used. Based on this information, it is assumed that the ambulance capacity varies between 1 and 4 . In addition, it is assumed that all ambulances have equal capacities. 
Number of Trips: The following formulation was used to determine the number of trips.

Table 4. Capacity distribution among three hospitals

\begin{tabular}{cccc}
\hline Trial & H1 & H2 & H3 \\
\hline 1 & 15 & $\mathrm{X}$ & $\mathrm{X}$ \\
2 & $\mathrm{X}$ & 15 & $\mathrm{X}$ \\
3 & $\mathrm{X}$ & $\mathrm{X}$ & 15 \\
4 & 15 & $\mathrm{X}$ & $\mathrm{X}$ \\
5 & 14 & $\mathrm{X}$ & 16 \\
6 & 18 & 12 & $\mathrm{X}$ \\
7 & $\mathrm{X}$ & $\mathrm{X}$ & 15 \\
8 & 20 & 15 & 10 \\
9 & 10 & 16 & 20 \\
10 & 20 & 15 & 9 \\
11 & 15 & 5 & 15 \\
12 & 20 & 40 & 20 \\
13 & 10 & 20 & 10 \\
14 & 20 & 15 & 20 \\
15 & 30 & 40 & 15 \\
16 & 16 & & 4 \\
\hline
\end{tabular}

Number of trips $=($ Total number of injured $) /($ Number of ambulances $\times$ Ambulance capacity)

The distribution of the number of ambulances, their capacities, the number of injuries, and trips among 16 trial runs are shown in Table 5.

Table 5. Distribution of ambulance numbers and capacities and the number of injuries-trips

\begin{tabular}{llrrr}
\hline Trial & \# of Amb. Amb. Capacity & \# of Injured & \# of Trips \\
\hline 1 & 2 & 1 & 10 & 5 \\
2 & 2 & 2 & 10 & 3 \\
3 & 2 & 3 & 10 & 2 \\
4 & 2 & 4 & 10 & 2 \\
5 & 4 & 1 & 20 & 5 \\
6 & 4 & 2 & 20 & 3 \\
7 & 4 & 3 & 20 & 2 \\
8 & 4 & 4 & 20 & 2 \\
9 & 6 & 1 & 30 & 5 \\
10 & 6 & 2 & 30 & 3 \\
11 & 6 & 3 & 30 & 2 \\
12 & 6 & 4 & 30 & 2 \\
13 & 8 & 1 & 40 & 5 \\
14 & 8 & 2 & 40 & 3 \\
15 & 8 & 3 & 40 & 2 \\
16 & 8 & 4 & 40 & 2 \\
\hline
\end{tabular}

The model that was developed along with all these data sets and the assumptions was solved using the GAMS software and the obtained results are provided in the next section.

\section{Conclusion and Recommendations}

In the light of the information given in Section 4, the model that was developed in Section 3 was tested and ambulance routing for Yalova province was examined for small-scale samples.

The responses of the system to the randomly distributed casualties vary when looking at the number of injured and their location, and the number and capacity of ambulances also affect the optimum or local optimum results of the system. The system was run 16 times in the mathematical model trials solved by the GAMS program. As a result of these studies, optimum results were obtained for 6 times (trials no. 1-2-3-4-5-13), and local optimum results were obtained for 10 times (acceptable results within acceptable periods). The system was run for trials for different periods and the results are shown in Table 6.

Table 6. Results and solution times of ambulance routing in GAMS program

\begin{tabular}{|c|c|c|c|c|}
\hline Trial & Result & Solution Time (sec) & Solver Status & Model Status \\
\hline 1 & 22356 & 0.113 & 1 & 1 \\
\hline 2 & 339 & 0.720 & 1 & 1 \\
\hline 3 & 119 & 1082.194 & 1 & 1 \\
\hline 4 & 91 & 301.423 & 1 & 1 \\
\hline 5 & 44644 & 0.720 & 1 & 1 \\
\hline 6 & 620 & 7198.129 & 3 & 8 \\
\hline 7 & 192 & 7198.067 & 3 & 8 \\
\hline 8 & 138 & 7198.129 & 3 & 8 \\
\hline 9 & 66972 & 10798.585 & 3 & 8 \\
\hline 10 & 946 & 10798.495 & 3 & 8 \\
\hline 11 & 345 & 7200.144 & 3 & 8 \\
\hline 12 & 275 & 7200.200 & 3 & 8 \\
\hline 13 & 89252 & 74.038 & 1 & 1 \\
\hline 14 & 1333 & 10801.107 & 3 & 8 \\
\hline 15 & 412 & 10800.351 & 3 & 8 \\
\hline 16 & 337 & 14403.123 & 3 & 8 \\
\hline
\end{tabular}

When we look at the trials with optimum results, the number of casualties appears as 10,20 , and 40, but ambulance capacities give optimum results in all values for only 10 injured (in trial studies no 1-2-3-4). Considering the trial studies with 20 and 40 injuries (trials 5 and 13), the system gives optimum results when the ambulance capacity is only 1. Considering these trials, the system worked for different periods for optimum or local optimum results. The optimum solution of some trials under different durations is shown in Table 5.1. The fact that the system has different solution times for the same number of casualties can be explained by the location of the injured and the change in ambulance capacities.

This study aims to develop and present a mathematical model within the context of post-disaster management. One of the directions for subsequent research is extending the geographic scope of the problem based on the current model which would significantly increase the problem size. Thus, the development of a special-purpose algorithm is another direction for future research.

\section{References}

[1] C. Sahin, S. Sipahioglu, Natural Disasters and Turkey (Expanded $2^{\text {nd }}$ Edition), Daytime Education and Publishing 472 Turkey (2003).

[2] T. Erkal, M. Degerliyurt, Disaster management in Turkey, Eastern Geographical Review 14 (22) (2009) 147-164.

[3] M. Tanyas, Y. Günalay, L. Aksoy, B. Kucuk, Istanbul province disaster logistics plan guide, Istanbul Development Agency 181 Turkey (2013).

[4] M. Agdas, O. Bali, H. Balli, Site selection for the distribution center within the scope of disaster logistics: an application 
with SMAA-2 technique, Beykoz Academy Journal 2 (1) (2014) 75-94.

[5] G. Barbarosoglu, L. Ozdamar, A. Cevik, An Interactive Approach for Hierarchical Analysis of Helicopter Logistics in Disaster Relief Operations, European Journal of Operational Research 140 (2002) 118-133.

[6] A. Kara, Cluster coverage problems aimed at maximizing network life. Master Thesis, Institute of Science, Erciyes University, Turkey (2014).

[7] E. Aktas, O. Ozaydın, F. Ulengin, E.Ş. Onsel, B. Agaran, A new model for the selection of fire station locations in Istanbul, Journal of Industrial Engineering 22 (2011) 2-12.

[8] B. Sezen, B. Erben, Positioning the bicycle which has an important place in sustainable transportation with the Gams cluster coverage model: Gebze Technical University example, Journal of Intelligent Transportation Systems and Applications 2 (2019) 42-56.

[9] Y.E. Ozturk, H. Oncel, E. Ordek, 112 emergency service stations settlement model in Konya-Selçuklu district, Selçuk University Journal of Engineering Science and Technology 1(1) (2013) 19-32.

[10] H.A. Sarikaya, H. Aygunes, A. Kilic. Determination of the location of the gendarmerie stations with the largest coverage method, Journal of Industrial Engineering 31 (2020) 28-47.

[11] B. Catay, A. Basar, T. Unluyurt. Planning the locations of emergency aid stations in Istanbul, Chamber of Mechanical Engineers Industrial Engineering Journal 19 (2008) 20-35.

[12] Y. E. Demirtas and E. Ozdemir, A New Solution Proposal for Dynamic Vehicle Routing Problems, Journal of Suleyman Demirel University Faculty of Economics and Administrative Sciences 22 (2017) 807-823.

[13] E. Duzakin, M. Demircioglu, Vehicle routing problems and solution methods, Journal of Cukurova University Faculty of Economics and Administrative Sciences 13 (2009) 68-87.

[14] A. Izadi, F. Jamshidpour, H. Hadizadeh, Evaluation of the Performance of Bus Special Lines According to Indicators of Quality and Transport, Computational Research Progress in Applied Science \& Engineering (CRPASE) 05 (2019) 105113.

[15] A. G. Matin, F. Moghadasnejad, Feasibility Study on Creation of Bike Paths Network in Urban Transport, Computational Research Progress in Applied Science \& Engineering (CRPASE) 01 (2015) 14-22.

[16] S. Yilmaz, Modeling of multi-warehouse vehicle routing problem with ant colony optimization and a solution proposal, Master Thesis, Institute of Science, Yildiz Technical University, Turkey (2008).

[17] E. Yildiz, Problems in multi-depot vehicle scheduling problems, Master Thesis, Institute of Engineering and Science, Sabanci University, Turkey (2011)

[18] E. Onder, Optimization of Multi-Depot Vehicle Routing Problem of Istanbul Halk Ekmek AS (IHE) by Using MetaHeuristic Methods, Istanbul University, Business Economy Institute Journal of Management 70 (2011) 74-92.

[19] O. Ozer, Multi-depot organ distribution practice in the Marmara region, Master Thesis, Institute of Science Yildiz Technical University, Turkey (2016).

[20] K. Kiziloglu, An intuitive solution approach to a stochastic demand multi-depot vehicle routing problem, Master Thesis, Institute of Science and Technology, Gazi University, Turkey (2017).

[21] M.H. Sadatizamanabad, Three-level multi-depot vehicle routing problem with warehouse protection and customer selection, PhD Thesis, Institute of Science and Technology, Koç University, Turkey (2018).

[22] D.G. Ozen, Modeling and solving the feeder bus network design problem as a multi-store open-ended vehicle routing problem, Master Thesis, Institute of Science, Pamukkale University, Turkey (2020).
[23] M. Mirabi, S.F. Ghomi, F. Jolai, Efficient stochastic hybrid heuristics for the multi-depot vehicle routing problem, Robotics and Computer-Integrated Manufacturing 26 (2010) 564-569. 